\title{
A reflexão colaborativa como propulsora da formação continuada de professores de Língua Inglesa mediante o uso das ferramentas virtuais ${ }^{1}$
}

Jesiel Soares-Silva*

Resumo: Este trabalho analisa uma pesquisa colaborativa desenvolvida por cinco professoras de Língua Inglesa da rede pública de Goiânia, Goiás, através das novas Tecnologias de Informação e Comunicação (TIC). O propósito maior foi averiguar de que forma a pesquisa colaborativa pode contribuir para uma prática docente menos individual no ensino mediado por computador e como a reflexão e a ação podem ser alternativas na formação das professoras. Os resultados apontam que a colaboração foi um fator decisivo na formação reflexiva e prática das professoras, pois compartilhando os avanços, angústias, entraves do trabalho entre si, os professores se sentem mais seguros e confiantes para prosseguir. Os resultados também mostram que a ação e a reflexão sobre a prática foram fundamentais para a construção de uma docência menos individual.

Palavras-chave: Reflexão colaborativa; Novas tecnologias; Formação de professores

Doutorando em Linguística pela UFMG. Mestre em Linguística Aplicada pela UFGO. Coordenador do grupo P.L.A.T.A.FORMA (Professor de Línguas: Autonomia, Tecnologia, Ação e Formação). Membro do grupo Tecnologias da Mediação e Experiências Multilíngues, vinculado à Pós-Graduação da UFMG. E-mail: fassiedojeb@ yahoo.com.br

1 Este artigo é fruto da dissertação de mestrado intitulada: Os desafios de navegar: a colaboração como buissola da formação contínua de professores de lingua inglesa mediante as novas TIC, defendida em fevereiro de 2012, sob a orientação da Profa. Dra. Eliane Carolina de Oliveira, na Universidade Federal de Goiás. 


\begin{abstract}
This work analyzes a collaborative research developed by five English language teachers of public schools in Goiânia, Goiás, through the new Information and Communication Technologies (ICT). The main purpose was to verify in which way the collaborative research may contribute to a less individual teaching practice in Computer Assisted Language Learning and how the reflection and the action may be alternatives in the teacher education. The results show that the collaboration was a decisive factor in the reflective and practical formation of the teachers, because by sharing the progress, the anguishes, the problems among the members of the group, the participant teachers felt more confident to keep going. The results also show that the action and the reflection on the practice were fundamental to the construction of a less individual teaching.
\end{abstract}

Keywords: Collaborative reflection; New Technologies; Teacher education

\title{
Introdução
}

Nos últimos anos muito tem-se discutido acerca da inserção das novas Tecnologias de Informação e Comunicação (TIC) no sistema educacional e nas formas com que o professor pode adaptar sua prática às novas contingências sociais propiciadas pelo constante avanço dos aparatos tecnológicos. Esse cenário requer que os professores busquem alternativas de uso das ferramentas virtuais em seu planejamento e atuação didática, sem transformá-las em um emaranhado tecnológico, desprovido de critérios pedagógicos ou, em casos mais extremos, cair no equívoco de tomá-las como a solução de todos os problemas da escola e do ensino.

O boom tecnológico proporcionado sobretudo pelos recursos da web 2.0 tem causado reações diversas nos professores, nos alunos e nos programas de formação docente. Em relação aos professores, por um lado existem aqueles que tomam as novas ferramentas virtuais como a solução dos problemas didáticos, 
estruturais e práticos do ensino e acreditam que utilizando games, redes sociais, vídeos em suas aulas estão transformando o tradicionalismo da sala em algo inovador.

Por outro lado, alguns professores se mostram negativos ao uso das novas TIC em suas práticas ${ }^{2}$. Isso se dá por diversas razões que vão desde a falta de habilidade com os computadores até a crença de que nos ambientes virtuais os aprendizes não focam nas atividades propostas e ficam demasiadamente "livres" da orientação do professor. Muitas dessas crenças residem na ideia de que a função do professor é a de transmitir conhecimento (FREIRE, 1996), portanto, se o aluno tiver acesso a um espaço virtual por intermédio de um número infindo de conexões, informações e comunicações, o professor perderia seu status de detentor do saber.

Para que o professor engendre nessas novas demandas tecnológicas de maneira a não considerá-las como a solução dos problemas, ou ignorá-las e continuar no tradicionalismo didático, é preciso que repensemos os papéis dos atores educacionais no processo, sobretudo do professor. Cabe, assim, perguntar: De que forma o professor pode acoplar as novas TIC na sua prática docente de forma a otimizar os resultados de sua atuação, e de que maneira essa tarefa deve ser pensada, levando em consideração o currículo, os alunos, a estrutura, o tempo disponível?

Pensando nessas questões, propomos este artigo que é fruto das discussões feitas em uma pesquisa de mestrado desenvolvida com cinco professoras da rede pública municipal e estadual de Goiânia, Goiás. Junto com essas participantes, e exercendo o papel de Assessor Acadêmico e mediador do projeto, propus a formação de um grupo de professores com o objetivo de apresentar, discutir e aplicar algumas ferramentas virtuais no ensino de língua inglesa. O objetivo maior da pesquisa foi entender como a reflexão, exercida de maneira colaborativa, pode contribuir para uma prática docente menos individual no ensino de língua inglesa mediado pelas ferramentas virtuais.

2 Cf. Robertson (2003). 
Primeiro apresentaremos uma concisa revisão teórica acerca do modelo de professor como profissional reflexivo bem como sobre a importância da colaboração no processo de formação continuada. Em seguida, descreveremos o contexto da pesquisa, participantes e métodos de coleta de dados. Por fim, serão apresentadas as considerações finais.

\section{O professor de língua em constante formação: reflexão, colaboração e tecnologia}

Nos últimos anos, várias pesquisas têm sido empreendidas na área de ensino de línguas mediante o uso das novas TIC (MORAN, 2000; PÓVOA, 2000; KENSKI, 2003; SHARMA e BARRET, 2007; PAIVA, 2011) bem como alguns trabalhos que tratam da formação de professores na perspectiva desse novo tempo tecnológico (SAMPAIO e LEITE, 2002; SCHNEIDER, 2007). Com a crescente facilitação do acesso às novas ferramentas tecnológicas e a evidente inserção de parte delas em alguns contextos educacionais, muitos trabalhos têm concentrado nesse aspecto. Porém, ainda há muito que se pesquisar sobre as questôes que envolvem a prática docente dentro desse conjunto das novas demandas tecnológicas.

Dentre os construtos acerca da formação docente, o modelo de professor como profissional reflexivo tem sido constantemente operado nos desdobramentos das teorizações e práticas acerca da atuação do professor. Como precursor do modelo de professor como profissional reflexivo, Schön (1983) conceitua primeiramente o professor pela racionalidade técnica. O professor técnico é aquele que aplica as atividades baseadas em procedimentos pré-estabelecidos e busca soluçôes para os problemas através de princípios gerais advindos de pesquisas anteriores. Por essa formulação, podemos entender que o professor busca a 
"solução instrumental de problemas mediante a aplicação de um conhecimento teórico e técnico" (CONTRERAS, 2002, p. 90). Schön (1983) definiu a reflexão em três momentos: Primeiro, a reflexão-na-ação, simultânea a atuação, na qual o professor reflete sobre os problemas postos no momento da prática e busca formas de minimizá-los. Através da reflexão na ação se torna possível interagir por intermédio do diálogo reflexivo com os problemas concretos (SCHÖN, 1983).

Segundo, a reflexão-sobre-a-ação, que acontece a posteriori e culmina em um processo mais criterioso, uma vez que não é afetado diretamente pelo momento da atuação. Esse tipo de reflexão envolve o uso do conhecimento no intuito de definir, descrever, analisar e até avaliar as reflexões feitas durante as ações e as intervenções anteriores.

Terceiro, a reflexão-sobre-a-reflexão-na-ação, que é tida como uma prestação de contas do professor. Esse tipo de metarreflexão é mais criteriosa, pois leva em conta um corpus de informações coletado durantes os períodos de reflexão e atuação nas aulas, no intuito de criar um paradigma de atuação guiado pela comparação, análise e julgamento desses vários momentos sistematicamente reflexivos.

Existem algumas críticas à teoria de Schön (1983) por ela se referir apenas à reflexão individual do professor, ignorando assim tanto o contexto de atuação quanto a participação de outros agentes no processo reflexivo. Liston e Zeichner (1991) e Day (1999) apontam para essas limitações ao proporem a colaboração e a contextualização do processo reflexivo como um desdobramento possível da teoria de Schön (1983).

Portanto, refletir sobre a atuação na prática configura-se como fundamental quando o que se busca são formas de agir levando em conta cada contexto específico de atuação. Essa reflexão, portanto, não pode ser feita de maneira individual e deslocada da comunidade escolar, mas colaborativamente com outros professores, com os alunos e com todos os participantes da prática docente. 
Durante a atividade profissional, o trabalho colaborativo e coletivo passa a ser fundamental nas tomadas de decisões futuras, na formulação de novos saberes, uma vez que o ambiente de atuação docente é formado por vários atores do processo: alunos, outros professores, a comunidade escolar, o próprio professor. Sendo assim, seria um equívoco refletir sobre a prática de maneira desvinculada desses integrantes. Moura (2004, p. 261), concordando com esse aspecto de colaboração, aponta que

[o] professor se forma ao interagir com os seus pares, movido por um motivo pessoal e coletivo. No seu motivo pessoal, está o conjunto de saberes e expectativas sobre a vida e os rumos que acredita serem válidos para empreender o seu trabalho. Os motivos coletivos são dados por acordos que se estabelecem entre os que constituem a escola como grupo.

Nos últimos anos, com o advento das novas TIC, os programas de formação de professores têm focado seus estudos na reflexão e na colaboração docente como uma alternativa para a inserção do professor nessa nova era. Para Prensky (2001), os professores são como imigrantes digitais em um sistema escolar composto de alunos nativos digitais e, nesse novo cenário, várias mudanças, tanto no papel do professor quanto no do aluno, se tornam necessárias, uma vez que a as novas tecnologias já estão, em certa medida, inseridas na educação.

Por conseguinte, trabalhar com as novas TIC implica repensar as formas de atuação e buscar maneiras de promover um ambiente propício à construção de conhecimento e não de transmissão de saberes. É preciso ainda que o professor construa uma prática baseada na reflexão e na interação com os alunos e outros professores. Para Dowbor (2000, p. 17):

[... no intuito de inserir as práticas escolares no atual cenário. Por vezes, notamos que a escola tem o incrível poder de se isolar do mundo e se privar das mudanças sociais e criar dentro de si uma rede de práticas e pensamentos que não condizem com a realidade tecnológica da comunidade escolar. 
Para Celani (2004, p. 40), "enquanto o mundo se move em velocidade supersônica, a escola, em muitos casos, ainda está caminhando na velocidade do carro de boi”.

Nos últimos anos, com o advento das novas TIC, os programas de formação de professores têm focado seus estudos na reflexão e na colaboração docente como uma alternativa para a inserção do professor nessa nova era. Para Prensky (2001), os professores são como imigrantes digitais em um sistema escolar composto de alunos nativos digitais e, nesse novo cenário, várias mudanças, tanto no papel do professor quanto no do aluno, se tornam necessárias, uma vez que a as novas tecnologias já estão, em certa medida, inseridas na educação.

\section{A pesquisa colaborativa: contextualização, participantes e procedimentos}

A complexidade conceitual e metodológica da pesquisa qualitativa exige dos participantes um envolvimento intenso com as etapas da pesquisa e a busca pela harmonia e a credibilidade entre os indivíduos se tornam fundamentais para um bom andamento do trabalho (CRESWELL, 2007). Portanto, o cenário da pesquisa de cunho qualitativo é um palco onde os problemas levantados são postos à prova e onde os novos saberes são construídos a partir dos alcances do fazer prático.

$\mathrm{Na}$ área de formação de professores, uma forma de pesquisa recorrente nos trabalhos é a pesquisa colaborativa (HARRY, 2007; LASSONDE; ISRAEL, 2010), modalidade na qual se insere o trabalho aqui apresentado. Essa modalidade de pesquisa, além de ressaltar as principais características da abordagem qualitativa, quando aplicada no trabalho docente, oferece ao professor a oportunidade de investigar sua própria prática e compartilhar suas ações em um processo de interação com outros professores. Para Magalhães (2004, p. 76): 
Colaborar, em qualquer contexto (pesquisa, formação contínua, sala de aula), significa agir no sentido de possibilitar que os agentes participantes tornem seus processos mentais claros, expliquem, demonstrem, com o objetivo de criar, para os outros participantes, possibilidades de questionar, expandir, recolocar o que foi posto em negociação.

Uma característica importante da pesquisa colaborativa, quando há o envolvimento de um grupo de professores, é o compartilhamento tanto de conhecimentos, informações, ideias quanto de angústias, questionamentos e frustrações. CochranSmith e Lytle (1993) asseveram que o desenvolvimento do grupo em um trabalho colaborativo acontece quando os participantes concebem o grupo como uma força coletiva propulsora de um tipo de trabalho que não poderia ser feito individualmente.

Ao participarem de uma pesquisa colaborativa que envolve a ação e a reflexão sobre o fazer docente, os professores realizam o que Lassonde e Israel (2010, p. 11) chamam de pensar junto, e no trânsito desse pensamento coletivo emergem as várias vozes imbuídas na construção de uma prática menos individual.

A pesquisa aqui apresentada foi desenvolvida entre outubro de 2010 e novembro de 2011. Após cinco professoras de inglês aceitarem o convite para participar da pesquisa, criamos o grupo P.L.A.T.A.FORMA (Professor de Línguas: Autonomia, Tecnologia, Ação e Formação), cujo intuito principal foi de apresentar, discutir e aplicar ferramentas virtuais na prática docente e refletir colaborativamente acerca dessa prática, buscando recorrências, limites, entraves e propondo ações e práticas. As ferramentas virtuais apresentadas por mim e pelas participantes foram Omegle, Lyrics Training, Akinator, Hangaroo, Blog ${ }^{3}$.

Assim o grupo de participantes dessa pesquisa, além da minha participação, foi composto por Bárbara, Fernanda, Helena, Marcela e Milena. Esses nomes são fictícios e foram escolhidos pelas próprias participantes.

3 Essas ferramentas estão gratuitamente disponíveis na internet nos respectivos endereços: <http://omegle.com>, <http://www.lyricstraining.com>, <http://en.akinator. com>, < http://www.hangaroo.info $>,<$ http://blogger.com $>$. Acesso em: 16 nov. 2011. 
Quadro 1: Síntese das participantes

\begin{tabular}{|c|c|c|c|}
\hline Participante & Experiência & $\begin{array}{l}\text { Turmas em que de- } \\
\text { senvolveu a pesquisa }\end{array}$ & $\begin{array}{l}\text { Ferramentas } \\
\text { utilizadas }\end{array}$ \\
\hline Bárbara & 11 anos & $\begin{array}{l}\text { Ens. Fund.: } 7^{\circ} \text { ano } \\
\text { (duas turmas) }\end{array}$ & $\begin{array}{l}\text { Lyrics Training, } \\
\text { Blog. }\end{array}$ \\
\hline Fernanda & 7 anos & $\begin{array}{l}\text { Ens. Fund.: } 1^{\circ} \text { período } \\
\text { (duas turmas) }\end{array}$ & Omegle e Blog \\
\hline Helena & $10 \mathrm{ar}$ & $\begin{array}{l}\text { Ens. Fund.: } 4^{\circ}, 5^{\circ} \text { e } 6^{\circ} \\
\text { períodos (três turmas) } \\
\text { Ens. Médio: } 1^{\circ} \text { ano } \\
\text { (uma turma) }\end{array}$ & $\begin{array}{l}\text { Omegle, Han- } \\
\text { garoo, Akinator, } \\
\text { Lyrics Training }\end{array}$ \\
\hline Marcela & 1 ano & $\begin{array}{l}\text { Ens. Médio: } 1^{\circ}, 2^{\circ} \text { e } 3^{\circ} \\
\text { anos }(6 \text { turmas })\end{array}$ & $\begin{array}{l}\text { Akinator, Han- } \\
\text { garoo, Omegle }\end{array}$ \\
\hline Milena & $\begin{array}{l}2 \text { anos } \\
\text { e meio }\end{array}$ & $\begin{array}{l}\text { Ens. Médio: } 1^{\circ}, 3^{\circ} \text { e } 5^{\circ} \\
\text { períodos (três turmas) }\end{array}$ & $\begin{array}{l}\text { Blog, Omegle, } \\
\text { Akinator, Lyrics } \\
\text { Training }\end{array}$ \\
\hline
\end{tabular}

Para coletar os dados da pesquisa fizemos uso de entrevistas semiabertas, feitas pelo sistema de chat; questionário acerca do perfil das participantes em relação ao tempo de experiência como docente e ao contato com as novas tecnologias; gravações em vídeo dos encontros presenciais do grupo P.L.A.T.A.FORMA; interações entre os participantes por meio de grupo virtual de discussão, feito pelo Yahoo, em que participantes expuseram o andamento de suas respectivas pesquisas, compartilhando avanços, limitações, dúvidas e sugestões.

\section{Análise e discussão dos dados}

No intuito de discutirmos os dados apresentados na pesquisa, analisaremos três aspectos do trabalho desenvolvido. Primeiramente, analisaremos a maneira com que as participantes entenderam e operaram os processos de colaboração propostos pelo grupo. Em seguida, abordaremos a questão da reflexão e 
da ação como construtos fundamentais no desenvolvimento do trabalho de cada participante. Por fim discutiremos os entraves e limitações do trabalho.

Em uma das interações pelo Grupo Virtual (GV), Milena congratula Helena pela forma interessante com que ela utilizou a ferramenta Lyrics Training. Helena não dispunha de computador e Internet em sua escola. Assim ela fez uso de seu computador pessoal projetando as páginas em uma tela para que todos pudessem acompanhar. Como o Lyrics Training é um jogo "pesado", quando há vários computadores conectados em uma mesma rede, a Internet tende a ficar "lenta", como no caso de Milena:

\section{Excerto 1:}

Helena, adorei a forma como você trabalhou com o Lyrics Training, pois também enfrento o mesmo problema de lentidão e queda de conexão durante as aulas em que utilizo vídeos ou programas pesados. (Milena - G.V. 01/03/2011)

Esse é um exemplo de que quando o professor atua de maneira aberta a outros professores e se mostra propenso à colaboração, ele poderá tanto influenciar nas ações dos outros professores quanto ser afetado por elas. Em outro momento de interação e colaboração entre ambas as participantes, Helena havia postado no $B \log$ um vídeo em que seus alunos faziam uma atividade de listening pelo Lyrics Training com uma música que a própria professora escolhera. Como havia apenas um computador, um aprendiz digitava enquanto os outros participavam com sugestôes. Percebemos que novamente o trabalho de Helena influencia nas ações de Milena, mas dessa vez Milena também faz sugestôes acerca do trabalho da colega:

\section{Excerto 2:}

Helena, adorei o seu Blog, inclusive optei em utilizar as outras ferramentas e realizar minha pesquisa por meio de um blog também! Achei superinteressante a atividade que você fez. Mas fiquei pensando aqui comigo se não seria mais interessante para os alunos, mais contextualizado ou até mesmo mais prazeroso (na hora de cantar) se você utilizasse uma música que eles gostem, de artistas conhecidos por eles, mesmo que tenha que fazer uma votação (porque agradar a todos em 
quesito musical será difícil, não é?). Acredito que quando a gente parte do que é real, do que faz parte do cotidiano dos alunos fica mais fácil internalizar o conteúdo e a língua além de permitir que eles realizem relações associativas durante as atividades. O que acha? (Milena - G.V. 14/03/2011).

Notamos que Milena elogia o trabalho de Helena e em seguida faz uma sugestão para o uso da ferramenta em questão. Isso nos evidencia que o trabalho colaborativo acontece de forma recíproca na interação das participantes. Quando, no trabalho colaborativo, os professores expõem seus problemas e avanços e abrem suas práticas à opinião dos colegas, eles têm a possibilidade de construir uma atuação mais abrangente e menos isolada.

A pesquisa colaborativa permite que os conhecimentos sejam construídos coletivamente durante o fazer da pesquisa e, com isso, o professor não age de forma individual. Acerca da sugestão de Milena no excerto anterior, Helena respondeu:

\section{Excerto 3:}

Eu concordo com você, quando eles cantam músicas escolhidas por eles mesmos, ficam mais animados. Eu só postei aquele vídeo porque queria postar logo alguma coisa, qualquer coisa. Eles cantam também Rhiana e Miley Cyrus, que eles adoram. O próximo vídeo vai ficar melhor, prometo. Valeu pela dica (Helena - G.V. 16/03/2011).

Percebemos nas interações entre Milena e Helena que a colaboração nos processos da pesquisa torna o trabalho do professor menos árduo, uma vez que ele não atua sozinho. A colaboração proporciona aos professores a possibilidade de construir sua prática de pesquisa amparados uns pelos outros, tanto no compartilhamento de ideias, problemas e avanços quanto nas contribuições práticas entre eles sobre os procedimentos do trabalho.

Retomamos aqui os conceitos de Anastasiou (2004) relacionados à ideia de que é fundamental, em um trabalho de grupo, a capacidade de um integrante trabalhar de maneira coletiva respeitando a singularidade, as aspirações e as emoções do seu colega. Além de configurar-se como um ambiente de compartilhamento 
de angústias, o grupo P.L.A.T.A.FORMA também serviu para que as participantes dividissem seus avanços e conquistas na pesquisa, fato esse que pode ser observado nas palavras de Milena:

\section{Excerto 4:}

Queria dividir uma coisa legal que aconteceu no meio da semana passada. Então, assim que apliquei o omegle com os alunos da turma $1^{\circ} \mathrm{b}$, eles comentaram com os alunos dos outros primeiros períodos. O que me deixou muito feliz. Mas o que mais me deixou feliz foi o fato de um grupo de alunos de outra sala me perguntarem quando irei utilizar o site que usei com os outros meninos, porque eles também queriam falar com os estrangeiros em inglês. Legal, né? É um sinal de que a ferramenta agradou e que também funcionou, não é? O que vocês acham? (Milena - G.V. 24/04/2011).

Pelas palavras de Milena, podemos notar que as interações virtuais entre os participantes do grupo consistiram em um espaço aberto de exposição do andamento do trabalho, bem como de postagens sobre conquistas e avanços. Assim como Milena, Helena tece um comentário elogioso sobre o trabalho, mas dessa vez sobre as ações de Fernanda. Os aprendizes de Fernanda desenvolveram seus próprios blogs em língua inglesa, formataram a página inicial de acordo com seus gostos (cores, fotos, símbolos) e fizeram postagens iniciais com informações pessoais. Pela interação entre as participantes percebemos que a motivação estimulada entre as colegas também foi um fator que contribuiu para o bom andamento da pesquisa do grupo P.L.A.T.A.FORMA:

\section{Excerto 5:}

Oi, pessoal. Gostei muito da forma com a qual a Fernanda está conduzindo a construção do(s) $b \log (s)$. Pelo que ela descreveu, os alunos ficaram interessadíssimos na aula. Dessa forma, nem parece aula e os alunos aprendem "sem sentir". O aprendizado flui. Fernanda, parabéns! (Helena - G.V. 30/04/2011).

Além de proporcionar às participantes a possibilidade de exporem suas dificuldades e avanços no trabalho, as açôes colaborativas do grupo também se mostraram importantes para 
a construção da experiência das participantes. Quando uma professora enfrentava algum problema com alguma ferramenta utilizada ou um entrave de outra ordem, ela podia contar com a experiência das outras.

Como já mencionado, algumas participantes possuíam mais tempo de trabalho que outras e, através dos diálogos, as professoras com menos tempo de atuação puderam adquirir mais experiência. Cabe aqui retomar as reflexões de Moura (2004) sobre a ideia de que através da interação com seus pares é que o professor se forma e que essa interação é movida tanto por motivos pessoais quanto coletivos, como podemos notar nas palavras de Marcela:

\section{Excerto 6:}

Sou bem nova na área, comecei a lecionar em agosto de 2010. Mas essa experiência com o grupo P.L.A.T.A.FORMA foi riquíssima. Na verdade, quando você lề os comentários das outras participantes fica mais aliviado, você percebe que o problema não acontece só com você ou só com seus alunos ou só na sua escola (Marcela - Entrevista).

Além da motivação e das angústias compartilhadas, as participantes também contribuíram para o fazer prático das colegas do grupo. Por diversas vezes, a forma com que uma participante aplicava determinada ferramenta e desenvolvia o trabalho influenciava diretamente as ações de outra participante que trabalhava a mesma ferramenta. Assim, as participantes puderam utilizar a experiência umas das outras com as ferramentas escolhidas para adaptar às suas.

Outro fator interessante foi que a intensidade com que as participantes se referiram ao trabalho colaborativo do grupo foi variada. De qualquer modo, todas as participantes apresentaram um feedback positivo em relação ao fator colaboração na pesquisa aqui apresentada. Nos excertos seguintes podemos perceber essas variações, quando as participantes foram perguntadas sobre o quão relevante foram as contribuições das colegas: 


\section{Excerto 7:}

Foram adequadas e oportunas, pois são profissionais opinando sobre o meu trabalho de um outro prisma, diferente do meu (Helena Questionário).

\section{Excerto 8:}

Fundamental! Foram as contribuições das outras participantes do grupo que me direcionaram para a ferramenta e o trabalho que eu iria desenvolver com os meus alunos. Além disso, foram estas mesmas contribuições que me fizeram sentir amparada, ao ver que elas compartilhavam dos mesmos problemas que eu na realização da pesquisa (Marcela - Questionário).

Podemos retomar aqui as ideias de Magalhães (2002, p. 51-52) de que "colaborar não significa simetria de conhecimento e/ou semelhança de ideias, [mas] conflitos, tensões e questionamentos". A mesma autora ainda afirma que na colaboração "as participações acontecem em níveis diferentes para cada participante, conforme o momento da pesquisa, o objetivo em agir e foco da discussão” (2002, p. 52). Essa assimetria em relação às participantes não foi um entrave pela pesquisa, pelo contrário constituiu-se como um fator fundamental nos momentos de troca de experiências entre as professoras.

Pelas palavras de Milena nos dois excertos seguintes percebemos que o grupo também contribuiu para que as professoras pudessem desenvolver o viés colaborativo de suas práticas docentes. Além disso, o grupo trabalhou a inserção das novas TIC nas aulas de língua inglesa de maneira mais interativa tanto para as professoras quanto para seus alunos, proporcionando aos professores a oportunidade de se desviar da racionalidade técnica (SCHÖN, 1983), buscando formas mais reflexivas de atuação:

\section{Excerto 9:}

O grupo contribuiu de fato durante as interações tirando dúvidas sobre as ferramentas, sobre ações em sala e na troca de experiências nos encontros presenciais. A pesquisa e o grupo fizeram com que eu olhasse minha sala de aula e meus alunos[...] de uma forma diferente, por exemplo, percebi a necessidade de aliar os recursos tecnológicos, 
principalmente a Internet no âmbito educacional principalmente para ensinar a língua estrangeira (Milena - Entrevista).

\section{Excerto 10:}

[...] pois, por meio das dúvidas e do resultado da pesquisa dos colegas do grupo consegui crescer como pesquisadora e trabalhar mais de forma colaborativa (Milena - Questionário).

Outro ponto importante a ser ressaltado em relação ao trabalho colaborativo implementado pelo P.L.A.T.A.FORMA foi o fato de que as participantes, até a proposta da formação do grupo, não haviam trabalhado colaborativamente em suas carreiras profissionais, ou seja, algumas delas já haviam desenvolvido pesquisa, mas nunca uma pesquisa colaborativa. Pelas palavras de Helena, podemos notar a importância do grupo na apresentação e aplicação dessa modalidade de pesquisa:

\section{Excerto 11:}

Mesmo antes de participar da pesquisa eu sempre procurei meios de investigar minha prática, agora o que foi novidade foi o fato de discutir em grupo e ser observada por outros profissionais. Isso dá um certo receio na hora de discutir as aplicações das atividades. Dá vergonha também, quando o entrave é a falta de conhecimento técnico. Mas o saldo é positivo, aprendi muito (Helena - Entrevista).

\section{Excerto 12:}

No grupo eu percebi que as dificuldades eram expostas, assim como as conquistas. Se uma participante pensava que estava fazendo "errado", ou estava atrasada, ou não tinha a habilidade necessária, então pelos comentários de outra participante, aquela acabava se animando e percebendo que não estava sozinha naquela situação. Tipo, as dificuldades enfrentadas pelos outros servia de consolo para cada participante (Helena - Entrevista).

Ao observarmos os dados apresentados sobre as ações da pesquisa colaborativa, os alcances do fazer prático das professoras e a maneira com que elas entenderam o trabalho, podemos fazer um balanço muito positivo em relação aos objetivos propostos neste trabalho. As professoras se engajaram no projeto de colaboração e fizeram do grupo P.L.A.T.A.FORMA um espaço 
democrático de opiniões sobre o trabalho docente, de partilha de saberes e de interação.

Outro aspecto importante no trabalho nos leva à segunda categoria de análise: reflexão e da ação como construtos fundamentais no desenvolvimento do trabalho de cada participante. $\mathrm{O}$ trabalho de reflexão colaborativa se mostrou profundamente importante durante a pesquisa, pois através das interações entre as professoras, juntamente com a minha participação como Assessor Acadêmico, várias ações foram implementadas, tanto em relação ao conjunto de atividades aplicadas nas aulas, como no aprimoramento tecnológico delas em relação às ferramentas da web.

Marcela, por sua vez, atribui à pesquisa docente a forma mais prática de se refletir sobre a atuação no intuito de buscar alternativas para um ensino que se aproxime mais dos aprendizes . Ao ser indagada sobre a relevância das reflexões feitas no grupo, ela respondeu:

\section{Excerto 13:}

Desde que comecei a pesquisa, tenho procurado pensar minha sala como um todo e buscar compreender as necessidades dos meus alunos [...] penso que pesquisa docente é aquela que avalia um ambiente real de sala de aula para refletir o que foi bom e o que deve ser mudado (Marcela - Entrevista).

Concordamos com Marcela quando ela afirma que a reflexão prática está relacionada diretamente com a ação, em outras palavras, ela aponta que refletir sobre a prática e agir sobre a prática são construtos que se complementam dentro do conjunto de tarefas do professor. Esse processo cíclico de ação/reflexão, entretanto, terá um alcance mais significativo se for realizado através da colaboração entre os professores, ou seja, se tanto a reflexão quanto à ação não for praticada de maneira isolada $\mathrm{e}$ individual. Nesse aspecto, as ações do grupo contribuíram pra que as professores refletissem sobre suas práticas e agissem no contexto escolar de forma coletiva: 


\section{Excerto 14:}

Eu achei muito proveitoso, pois pude refletir sobre minhas estratégias em sala, assim como atividades, planejamentos e recursos. Ganhos tive vários, como a melhoria no desenvolvimento das minhas aulas, na interação com os aluno e também a experiência em navegar em novos mundos, ferramentas (Milena - Entrevista).

Nas palavras de Marcela podemos perceber a importância da reflexão na reconstrução constante da prática docente. Em outras palavras, a mudança provocada a partir da reflexão não é definitiva, pois a formação do professor é um processo contínuo, inacabado e em constante transformação. Como foi apresentado no quadro 1, Marcela era a participante com menos tempo de atuação docente e, nos processos de reflexão e colaboração do grupo, ela pôde refletir sobre sua prática e mostrou propícia a mudanças:

\section{Excerto 15:}

Sinceramente, foi difícil, porque percebi o quanto de falhas eu ainda tenho. Como você [Assessor Acadêmico] mesmo me disse uma vez, "refletir doi" no sentido de você ver as falhas, querer melhorá-las e conseguir, daí enxerga novas falhas e quer melhorá-las também, a coisa não acaba nunca! Percebi o quanto as minhas aulas as vezes são chatas para os meus alunos. Eu acho que eu mesma não suportaria por muito tempo (Marcela - Entrevista).

Como afirmou Marcela, a reflexão sobre nossa prática como professores é por vezes um processo árduo, pois passa pelo conhecimento das nossas limitações e pela vontade de crescer profissionalmente. Marcela reflete no nível prático ao considerar e julgar sua atuação a partir de suas ações em sala e é interessante ressaltar que essa reflexão se deu devido à colaboração com o grupo.

Durante o processo do trabalho desenvolvido pelas participantes, podemos observar, através da colaboração entre elas e dos momentos de interação ocorridas no grupo tanto nos ambientes virtuais quanto nos encontros presenciais, que os caminhos foram sendo construídos e reconstruídos ao longo do processo: 
Excerto 16:

$\mathrm{Eu}$ mudei tantas vezes o foco da minha pesquisa, conforme fui aplicando as atividades e colhendo depoimentos, a própria pesquisa foi me conduzindo por caminhos. Ela ganhou vida própria (Helena - G. V. $30 / 04 / 2011)$.

Nas palavras de Helena, temos um exemplo de que o trabalho docente desenvolvido através da reflexão e da colaboração não possui um percurso pré-definido, pois é na interação com os pares e no transcorrer do trabalho que os rumos da investigação vão se consolidando. Esse dado corrobora com a definição da pesquisa qualitativa, apresentada no capítulo metodológico, de que o foco está no processo e não no produto, em outras palavras, o objetivo da pesquisa reside justamente nos rumos que ela toma.

Uma das ideias que fazem com que os professores não utilizem os recursos da web em suas práticas é a crença de que os alunos da escola pública não têm acesso a Internet, ou de que esse acesso só acontece na escola. Dessa forma, por causa das condições precárias dos laboratórios, seria inviável trabalhar com recursos virtuais. Essa crença faz com que os professores não ajam sobre essa realidade com vistas a transformá-la e, por vezes, se sentem satisfeitos com a ideia de que não há nada o que fazer.

Durante o trabalho das professoras do grupo P.L.A.T.A.FORMA pudemos observar que, apesar das limitações tecnológicas e das condições dos laboratórios, os problemas relacionados com o acesso à Internet não configuraram uma barreira insuperável pois, através da reflexão colaborativa entre as colegas juntamente com a atitude de ação de cada uma, esses entraves foram minimizados.

Em seu trabalho, Helena fez um levantamento sobre o acesso dos seus alunos à Internet, lembrando que todas as ações das professoras participantes foram implementadas em escolas públicas. Pelos dados, notamos que no trabalho dela o acesso à rede não constituiu uma limitação para as ações implementadas: 
Quadro 2: Dados de Helena sobre o acesso dos alunos à web

\begin{tabular}{|c|c|c|c|c|c|}
\hline Turma & $\begin{array}{c}\text { Idade } \\
\text { aproximada }\end{array}$ & $\begin{array}{c}\text { Alunos } \\
\text { presentes }\end{array}$ & $\begin{array}{c}\text { Acesso à } \\
\text { web em } \\
\text { casa }\end{array}$ & $\begin{array}{c}\text { Acesso à } \\
\text { web } \\
\text { em outros } \\
\text { lugares }\end{array}$ & $\begin{array}{c}\text { Total } \\
\text { dos alunos } \\
\text { com acesso }\end{array}$ \\
\hline D1 & 09 anos & 23 & 10 & 7 & $73,9 \%$ \\
\hline D2 & 09 anos & 21 & 10 & 7 & $\mathbf{8 0 , 9 \%}$ \\
\hline E1 & 10 anos & 22 & 10 & 11 & $\mathbf{9 5 , 4 \%}$ \\
\hline E2 & 10 anos & 24 & 09 & 12 & $\mathbf{8 7 , 5 \%}$ \\
\hline F1 & 11 anos & 20 & 12 & 07 & $\mathbf{9 5 \%}$ \\
\hline F2 & 11 anos & 21 & 13 & 08 & $\mathbf{1 0 0 \%}$ \\
\hline
\end{tabular}

Ao observarmos o Quadro 2, percebemos que o número de alunos de Helena que têm acesso à Internet, seja em casa, seja em outros ambientes, é considerável. Dos 131 aprendizes perguntados, 116 têm acesso à Internet, isto é, 88,5\% dos alunos de Helena têm acesso frequente à Internet. Em nossa opinião, esse é um número satisfatório para que o professor utilize a Internet com os alunos na escola e/ou nos ambiente virtuais fora do período das aulas.

É importante ressaltar que o levantamento de Helena não configura o panorama geral das escolas públicas em Goiás, muito menos no Brasil. Entretanto ele nos chama a atenção para o fato de que a ideia propagada sobre o aluno da escola pública não ter acesso à web deve ser repensada e analisada cuidadosamente em cada contexto de atuação. $\mathrm{O}$ professor não deve tomar como verdade essas crenças sobre a Internet, ao invés disso, deve pesquisar seus ambientes de atuação, como Helena o fez, no intuito de traçar um panorama sobre as condições da escola e dos alunos em relação ao computador com o propósito de agir e refletir sobre esse contexto, a fim de melhorá-lo.

Como toda pesquisa que envolve os processos educacionais, sobretudo as que envolvem as novas TIC, o trabalho desenvolvido enfrentou limitações de várias ordens. Por isso passamos 
à terceira categoria de análise. Bárbara expõe as dificuldades enfrentadas em relação à utilização do Lyrics Training e do Blog.

\section{Excerto 17:}

$\mathrm{Na}$ atividade do Lyrics Training, a Internet pesou bastante e nem todos conseguiram concluir ou até mesmo começar a atividade, já que alguns computadores não conseguiram carregar a música. A atividade do Blog demorou mais tempo do que eu imaginei, pois muitos dos alunos não tinhame-mail, o que pra mim foi uma surpresa, já que eles gostam tanto de computador e amam Orkut. (...) Mas, de qualquer forma, valeu a pena! (Bárbara - Questionário).

Um dos percalços mais difíceis das participantes desta pesquisa foi o que Helena enfrentou em seu trabalho. A escola onde a participante atua não possui laboratório de informática, por isso Helena precisou fazer uso de um laptop conectado à Internet móvel e projetá-lo no data show. Assim, enquanto alguns alunos praticavam a atividade no computador, os outros colaboravam com sugestões e ideias, e assim os alunos se revezavam no uso do recurso. Outra alternativa de Helena foi demonstrar a ferramenta durante as aulas e depois pedir para que em casa, ou em outro lugar de acesso à rede, os alunos desenvolvessem tarefas. Essa forma de uso da Internet trouxe alguns problemas para o trabalho dela:

\section{Excerto 18:}

Nem todos os alunos puderam participar, por falta de laboratório de informática na escola, as atividades foram demonstradas em sala de aula, pelo data show e desenvolvidas como homework (Helena - Questionário).

Além dos problemas relacionados diretamente às questões técnicas, algumas participantes enfrentaram limitações de outra ordem, como por exemplo, o agendamento de horários no laboratório, ou a adequação das ferramentas em algumas turmas. Percebemos esses entraves nas palavras de Fernanda e Marcela: 


\section{Excerto 19:}

[...] a Internet as vezes que falhava ou era lenta e os entraves dos estagiários (Fernanda - Entrevista).

\section{Excerto 20:}

[...] alguns poucos alunos acharam o jogo [Hangaroo] infantil (Marcela - Questionário).

Muitas vezes, os entraves enfrentados pelas participantes atrapalhavam em grande medida o andamento das ações delas, tornando o processo mais árduo do que o esperado em uma pesquisa docente. Nas palavras de Fernanda, podemos notar que ela enfrentou diversos percalços na realização do seu trabalho:

\section{Excerto 21:}

Olá todos do grupo. De volta, depois de uma temporada sem acessar aqui os e-mails de vocês. Tive mais de um mês sem utilizar o laboratório da escola porque estava com problemas na Internet local da escola e o pessoal que dá assistência é de outra cidade (Fernanda - G.V. 05/04/2011).

Nos excertos 22 e 23, Helena aponta os possíveis problemas enfrentados quando desenvolveu seu trabalho. Entretanto, ela também mostra que os alunos têm acesso à Internet em outros ambientes, e que o professor deve usar isso a seu favor para minimizar os problemas com o acesso à web na escola:

\section{Excerto 22:}

Os computadores e a Internet são ferramentas úteis demais nas aulas de Inglês, ao ponto de valer a pena superar problemas e limitações. $\mathrm{Na}$ escola onde eu trabalho não há computadores para uso dos alunos e mesmo assim, eu não poderia trabalhar à margem das possibilidades oferecidas na web, porque os alunos podem acessar fora do ambiente escolar e eles o fazem (Helena - Entrevista).

\section{Excerto 23:}

O que os professores precisam fazer é correr o risco, começar a usar e aprender enquanto utiliza (Helena - Entrevista). 
Assim como Helena, Fernanda demonstra ter enfrentado vários problemas durante seu trabalho, mas da mesma forma, afirma que esses problemas não podem ser a causa de os professores desistirem do trabalho de pesquisa, uma vez que podem ser contornados com força de vontade e criatividade:

\section{Excerto 24:}

[...] depende do professor. Sempre tem um jeitinho, os computadores estão lá, e é possível utilizá-los sim, mesmo sendo lento algumas vezes, é possível sim. É necessário planejar, estar preparado para as eventualidades, vai que uma hora não tem energia ou algo assim. [...] se não vai de um jeito vai de outro! O importante é você acreditar e jogar todas as cartas que você tem na mão (Fernanda - Entrevista).

Um importante ponto a discutir, quando o assunto são os problemas práticos apresentados aos professores no momento de um trabalho com as novas TIC na escola pública, é a questão da ação. Quando o professor, mesmo cercado de entraves à sua prática, age sobre ela, buscando formas de sobressair e desenvolver o seu trabalho, ele poderá, durante a ação, refletir e buscar alternativas para as suas aulas. A ideia de ação é bem definida nas palavras de Milena:

\section{Excerto 25:}

[...] eu acredito que obstáculos irão sempre existir, mas se você tem criatividade e alguns recursos, é possível superar essa situação. $\mathrm{Na}$ minha escola mesmo não tive acesso ao computador o tempo todo e nem para todos os alunos, então busquei utilizar o data show e meu próprio computador para realizar essa atividade e também acho que quando queremos mudar uma situação, não devemos só criar hipóteses de saídas, soluções, precisamos agir, foi o que eu fiz. Meus alunos são de situações econômicas diversas [...] então como sei que eles acessam a net para ver Orkut e outras redes sociais, pedi que acessassem os sites que utilizei durante a pesquisa nesses momentos. É claro que uns não tinham como, então reservei horários para eles no laboratório e eles mesmos tiveram a proatividade de reservarem o laboratório para realizarem as atividades. Enfim, eu acredito que é preciso na verdade ter muita criatividade, força de vontade, acreditar no seu trabalho e nos seus alunos e agir; obstáculos sempre existirão e estarão lá justamente para superarmos (Milena - Entrevista). 
Pudemos observar através dos dados apresentados que, por vezes, as ferramentas tecnológicas trabalhadas pelas professoras apresentaram dificuldades quanto à aplicação, bem como os problemas com o acesso à web e a condição estrutural dos laboratórios de informática. Por vezes, as limitações também foram de ordem organizacional e disciplinar.

Entretanto, pelas falas das professoras, notamos que esses problemas não constituíram um impedimento para que o trabatho fosse desenvolvido, pois as participantes aceitaram o desafio de enfrentá-los e, de forma colaborativa, propuseram alternativas de contornar esses problemas tornando possíveis suas ações.

\section{Considerações finais}

Como pudemos perceber nos dados, no início da pesquisa algumas das professoras já haviam desenvolvido pesquisa sobre suas práticas e possuíam uma ideia formada sobre o fazer investigativo docente, entretanto nenhuma delas havia trabalhado em colaboração com outros professores, por isso a pesquisa colaborativa constituiu uma novidade na carreira de todas as participantes. Já o construto ação permeou as falas de todas elas quando perguntadas sobre o que é a pesquisa docente; foi unânime a ideia de que a pesquisa do professor envolve agir sobre a prática na busca de novas alternativas de atuação.

A colaboração neste trabalho pode ser considerada como construto fundamental na pesquisa e na formação das professoras também pelo fato de que houve um compartilhamento de experiências entre todas. Como vimos nos dados, algumas professoras possuem mais tempo de carreira e experiência que outras, por isso a partilha de conhecimentos foi fundamental tanto para o ganho de experiência de umas quanto para a aquisição de novas experiências para outras.

Quando se trata de um trabalho que envolve um grupo de professores, pode-se pensar na questão da assimetria existente 
como um entrave em potencial posto ao trabalho. Entretanto, no trabalho colaborativo, essa assimetria é justamente o fator que mais contribui para a construção das práticas implementadas, uma vez que cada participante em sua singularidade e particularidade tem muito a contribuir com seu par e, simultaneamente, tem muito que aprender com seu par. Em outras palavras, quanto maior as diferenças entre os participantes, maiores serão as possibilidades de colaboração entre eles, como pudemos averiguar nos dados.

Quando busca refletir sobre sua prática dentro da colaboração, o professor foge do individualismo e da concepção de professor como detentor do conhecimento, pois ele constrói novos saberes através da relação com seus pares. Esse caráter dialógico da formação docente pelo viés da colaboração subsidia o conceito de professor reflexivo que buscamos com este trabalho.

É importante esclarecer que não estamos determinando a colaboração como a solução para todos os problemas contidos na formação de professores de língua, mas como uma alternativa a mais nesse processo. Como percebemos, ainda há muito que se discutir e desenvolver na formação de professores mediante o constante avanço das tecnologias, pois se trata de um cenário instável e em constante mudança. Por isso, entendemos que o trabalho colaborativo pode minimizar algumas barreiras existentes entre o docente de línguas tido como imigrante digital e as novas TIC.

Em relação às ferramentas discutidas e aplicadas pelas professoras, podemos dizer que mesmo com os entraves recorrentes quando da utilização da Internet, como falta de computadores, acesso limitado ou muito lento, além de questões como agendamento e horários, as professoras puderam desenvolver de forma satisfatória seus trabalhos. É importante retomarmos aqui a questão sobre a reflexão das participantes já discutidas no trabalho.

De forma geral, podemos dizer que as novas TIC, representadas pela Internet, se constituíram em uma forte aliada no trabalho docente das professoras. Mesmo que alguns casos 
tenha havido entraves à aplicação desses recursos, as professoras refletiram e agiram colaborativamente sobre esses problemas e buscaram minimizá-los.

A formação de professores mediante o uso das novas TIC consiste em um campo de estudo muito vasto. É necessário compreender as novas formas de atuação docente diante deste cenário no intuito de buscar alternativas de uma educação menos individual. É preciso ainda que a reflexão e ação do professor sejam feitas colaborativamente e não de maneira isolada.

\section{Referências}

ANASTASIOU, Lea das Graças Camargo. Profissionalização continuada: aproximações da teoria e da prática. In: BARBOSA, Raquel Lazzari Leite (Org.). Trajetórias e perspectivas da formação de educadores. São Paulo: Editora UNESP, 2004, p. 475-496.

CELANI, Maria Antonieta. Culturas de aprendizagem: risco, incerteza e educação. In: MAGALHÃES, Maria Cecília C. (Org.) A formação do professor como um profissional crítico. Campinas: Mercado das Letras, 2004, p. 37-56.

COCHRAN-SMITH, Marilyn; LYTLE, Susan Landy. Inside/outside: teacher research and knowledge. New York: Teachers College Press, 1993.

CONTRERAS, José. A autonomia de professores. Tradução de Sandra Trabucco Valenzuela. São Paulo: Cortez, 2002.

DAY, Christopher. Desenvolvimento profissional de professores: os desafios da aprendizagem permanente. Porto: Porto Editora, 1999.

DOWBOR, Ladislau. A educação frente às novas tecnologias do conhecimento. 2000. Disponível em <http://www.ppbr.com/ld/educfrente.html> Acesso em: 22 abr. 2009.

FREIRE, Paulo. Pedagogia da autonomia. Saberes necessários à prática educativa. São Paulo: Paz e Terra, 1996.

HARRY, Tyson. Collaborative Research and Development Projects. A practical guide. New York: Springer, 2007. 
KENSKI, Vani Moreira. Novas tecnologias na educação presencial e a distância I. In: BARBOSA, Raquel Lazzari Leite (Org.). Formação de educadores: desafios e perspectivas. São Paulo: Editora UNESP, 2003, p. 91-108.

LASSONDE, Cynthia A.; ISRAEL, Susan E. Teacher collaboration for professional learning. Facilitating study, research and inquiry communities. San Francisco: Jossey-Bass, 2010.

LISTON, Daniel P.; ZEICHNER, Kenneth M. Teacher Education and the social conditions of schooling. New York: Routledge, 1991.

MAGALHÃES, Maria Cecília C. A linguagem na formação de professores como profissionais reflexivos e críticos. In: MAGALHÃES, Maria Cecília C. (Org.) A formação do professor como um profissional crítico. Campinas: Mercado das Letras, 2004, p. 59-85.

MORAN, José Manuel. Ensino e aprendizagem inovadores com tecnologias audiovisuais e telemáticas. In: MORAN, José Manuel; MASETTO, Marcos T.; BEHRENS, Marilda A. Novas tecnologias e mediação pedagógica. 15. Ed. Campinas: Papirus, 2000, p. 11-64.

MOURA, Manoel Oriosvaldo de. Pesquisa colaborativa: um foco na ação formadora. In: BARBOSA, Raquel Lazzari Leite (Org.). Trajetórias e perspectivas da formação de educadores. São Paulo: Editora UNESP, 2004, p. 257-284.

PAIVA, Vera L. M. O.; BRAGA, Junia. Reconfigurando a sala de aula em ambientes virtuais de aprendizagem. In: BARCELOS, Ana Maria Ferreira. (Org.). Linguística aplicada: reflexões sobre o ensino e aprendizagem de língua materna e língua estrangeira. Campinas: Pontes, 2011, p. 119-139.

PÓVOA, Marcello. Anatomia da internet: investigações estratégicas sobre o universo digital. Rio de Janeiro: Casa das Palavras, 2000.

PRENSKY, Marc. Digital natives, digital immigrants. On Horizon (MCB University Press), Oct. 2001, v. 9, n. 5.

ROBERTSON, Heather-Jane. Toward a theory of negativity: Teacher education and information and communications technology. Journal of Teacher Education, v. 54, n. 4, 2003, p. 280-296. Disponível em: <http:// www.mathed.byu.edu/kleatham/Classes/Summer2006/RobertsonTowardATheoryOf negativity.pdf> Acesso em: 20 jul. 2011. 
SAMPAIO, Marisa Narciso; LEITE, Lígia Silvia. Alfabetização tecnológica do professor. 3. Ed. Petrópolis: Vozes, 2002.

SHARMA, Pete; BARRET, Barney. Blended learning: using technology in and beyond the language classroom. Oxford: Macmillan, 2007.

SCHNEIDER, Jeremy. Chalkbored: What's wrong with the school and how to fix it? USA: Peace of Mind, 2007.

SCHÖN, Donald Alan. The reflective practioner: how professionals think in action. London: Temple Smith, 1983.

ZEICHNER, Kenneth M. Educating reflective teachers for learner centered-education: possibilities and contradictions. In: GIMENEZ, Telma (Org.). Ensinando e aprendendo inglês na universidade: formação de professores em tempos de mudança. Londrina: ABRAPUI, 2003, p. 3-19. 


\section{ANEXO A}

\section{QUESTIONÁRIO}

Nome:

l - Marque um X no(s) seus(s) nível(is) de formação acadêmica/profissional (pode ser mais de um: Graduada e Especialista, por exemplo).

a - ( ) Cursando a graduação; b - ( ) Graduada; c - ( ) Cursando especialização; d - ( ) Especialista; e - ( ) Cursando o mestrado; f - ( ) Mestre; g - ( ) Cursando o doutorado; h - ( ) Doutora; i ( ) Outros:

2 - Há quanto tempo você é professora atuante de língua inglesa?

3 - Em qual(is) tipos de instituição você já atuou como professora de língua inglesa?

a - ( ) Escola Pública; b - ( ) Escola Particular; c - ( ) Curso de Idiomas; d - ( ) Faculdade; e - ( ) Outros:

4 - Em qual(is) nível(is) você leciona língua inglesa atualmente?

a - ( ) Ensino Fundamental; b - ( ) Ensino Médio; c - ( ) Ensino Superior

5 - De que local você acessa a Internet mais frequentemente? $\mathrm{a}-$ ( ) casa; b - ( ) trabalho; $\mathrm{c}-($ ) lan house; $\mathrm{d}-$ ( ) outros:

6 - Como você considera o seu acesso à Internet?

$\mathrm{a}-$ ( ) raro; b- ( ) esporádico; c- ( ) regular; $\mathrm{d}-($ ) frequente;

$\mathrm{e}-($ ) outra resposta: 
7 - Antes do desenvolvimento desta pesquisa do grupo P.L.A.T.A.FORMA você já havia utilizado a Internet nas aulas de língua inglesa? Se sim, que tipos de ferramentas? Quais?

8 - Na pesquisa do nosso grupo P.L.A.T.A.FORMA quais ferramentas você utilizou? Em quais turmas?

9 - De que forma você tomou conhecimento dessas ferramentas utilizadas?

10 - Que tipos de atividades você propôs com cada uma das ferramentas?

11- Quais foram seus objetivos ao usar essas ferramentas?

12 - Quais foram os pontos positivos (se houve) e/ou negativos (se houve) de cada ferramenta que você utilizou na pesquisa?

13 - O local onde você atua dispõe de quais recursos?

a - ( ) laboratório de Informática; b - ( ) acesso à Internet [Internet muito rápida ( ) rápida ( ) lenta ( ) muito lenta ( )]; c-( ) fones de ouvido/microfones nos computadores; $\mathrm{d}-$ ( ) Webcams nos computadores; e - ( ) Internet sem fio (wireless)

14 - Em quanto tempo você desenvolveu a pesquisa? Em quantas aulas? Quantas vezes você utilizou o laboratório?

15 - Quais foram (se houve) as limitações da sua pesquisa, tanto de ordem estrutural, acadêmica, pessoal, prática, técnica, institucional, organizacional?

16 - De forma geral, como foi a receptividade dos alunos em relação às ferramentas que você utilizou? 
17 - Com que frequência seus alunos, de forma geral, têm acesso à Internet?

$\mathrm{a}-$ ( ) raramente; $\mathrm{b}-($ ) esporadicamente; $\mathrm{c}-($ ) regularmente; $\mathrm{d}-$ ( ) frequentemente; $\mathrm{e}-($ ) diariamente; $\mathrm{f}-($ ) outra resposta:

18- De que maneira a escola que você pesquisou, representada pelo diretor, coordenadores e outros professores, recebeu sua pesquisa?

19 - Como você avalia o seu desempenho e participação na pesquisa do grupo P.L.A.T.A.FORMA?

20 - Como você avalia o seu desempenho nas interaçóes do grupo P.L.A.T.A.FORMA feitas através do yahoo?

21 - Como você avalia sua autonomia no desenvolvimento da sua pesquisa?

22 - Qual foi a relevância das contribuiçóes e das ideias das suas colegas do grupo na sua pesquisa?

23 - Qual foi importância da pesquisa na sua prática docente?

24 - Você pretende continuar usando as ferramentas na sua prática docente? Comente.

25 - Qual sua opinião geral sobre a formação, atuação e desenvolvimento do grupo P.L.A.T.A.FORMA e da pesquisa que você participou ?

26 - Por uma questão de ética, seu nome não será mencionado na pesquisa e será utilizado um pseudônimo. Qual o nome fictício você escolhe para ser usado quando eu me referir a você na minha dissertação? 


\section{ANEXO B}

\section{Roteiro de perguntas para a entrevista}

l - Qual sua visão geral acerca do trabalho que desenvolvemos?

2 - Como foi pra você, pesquisar sua própria prática? Dificuldades, ganhos, entraves.

3 - Quais foram (se houve) as contribuições efetivas, concretas do grupo P.L.A.T.A.FORMA e da pesquisa nas suas aulas?

4 - Você considera esse estudo desenvolvido com seus alunos uma pesquisa? Comente.

5 - Qual foi a importância das outras professoras, do trabalho delas e da interação que tivemos no grupo, para a sua pesquisa?

6 - Em sua opinião, qual a consequência da sua pesquisa para os seus alunos?

7 - Quais foram as limitações que você enfrentou para desenvolver o trabalho?

8 - Você já havia trabalhado colaborativamente com outros professores? Se sim, como foi? Se não, o que houve de proveitoso?

9 - Um dos objetivos desta pesquisa foi o de manter um tipo de vínculo entre o professor em serviço na escola pública com a universidade. Qual a importância disso em sua opinião? 